\title{
Clinical features and predictors for patients with severe SARS-CoV-2 pneumonia at the start of the pandemic: a retrospective multicenter cohort study
}

Chao Cao ${ }^{1 \dagger}$, Li He${ }^{2 \dagger}$, Jingping Ma ${ }^{2 \dagger}$, Meiping Chen ${ }^{1}$, Yiting Li ${ }^{1}$, Qingwen Jiang ${ }^{1}$, Shiyu Wu', Lili Yu², Weina Huang ${ }^{1}$, Guoqing Qian', Chuanbing Zhu², Jinguo Chu ${ }^{1}$ and Xiaomin Chen ${ }^{3^{*}}$

\begin{abstract}
Background: This study was performed to investigate clinical features of patients with severe SARS-CoV-2 pneumonia and identify risk factors for converting to severe cases in those who had mild to moderate diseases at the start of the pandemic in China.

Methods: In this retrospective, multicenter cohort study, patients with mild to moderate SARS-CoV-2 pneumonia were included. Demographic data, symptoms, laboratory values, and clinical outcomes were collected. Data were compared between non-severe and severe patients.

Results: 58 patients were included in the final analysis. Compared with non-severe cases, severe patients with SARS-CoV-2 pneumonia had a longer: time to clinical recovery (12.9 \pm 4.4 vs $8.3 \pm 4.7 ; P=0.0011)$, duration of viral shedding (15.7 \pm 6.7 vs $11.8 \pm 5 \cdot 0 ; P=0.0183)$, and hospital stay $(20.7 \pm 1.2$ vs $14.4 \pm 4.3 ; P=0.0211)$. Multivariate logistic regression indicated that lymphocyte count was significantly associated with the rate of converting to severe cases (odds ratio $1.28,95 \% \mathrm{Cl} 1.06-1.54$, per $0.1 \times 10^{9} / \mathrm{L}$ reduced; $P=0.007$ ), while using of low-to-moderate doses of systematic corticosteroids was associated with reduced likelihood of converting to a severe case (odds ratio $0.14,95 \% \mathrm{Cl} 0.02-0.80 ; P=0.0275$ ).
\end{abstract}

Conclusions: The low peripheral blood lymphocyte count was an independent risk factor for SARS-CoV-2 pneumonia patients converting to severe cases. However, this study was carried out right after the start of the pandemic with small sample size. Further prospective studies are warranted to confirm these findings.

Trial registration: Chinese Clinical Trial Registry, ChiCTR2000029839. Registered 15 February 2020 - Retrospectively registered.

Keywords: SARS-CoV-2, Pneumonia, Lymphocyte counts, Corticosteroids, Risk factors

\footnotetext{
* Correspondence: chxmin@hotmail.com

${ }^{+}$Chao Cao, Li He and Jingping Ma contributed equally to this work.

${ }^{3}$ Department of Cardiology, Ningbo First Hospital, 59 Liuting Road, Ningbo,

Zhejiang, China

Full list of author information is available at the end of the article
}

(c) The Author(s). 2021 Open Access This article is licensed under a Creative Commons Attribution 4.0 International License, which permits use, sharing, adaptation, distribution and reproduction in any medium or format, as long as you give appropriate credit to the original author(s) and the source, provide a link to the Creative Commons licence, and indicate if changes were made. The images or other third party material in this article are included in the article's Creative Commons licence, unless indicated otherwise in a credit line to the material. If material is not included in the article's Creative Commons licence and your intended use is not permitted by statutory regulation or exceeds the permitted use, you will need to obtain permission directly from the copyright holder. To view a copy of this licence, visit http://creativecommons.org/licenses/by/4.0/. The Creative Commons Public Domain Dedication waiver (http://creativecommons.org/publicdomain/zero/1.0/) applies to the data made available in this article, unless otherwise stated in a credit line to the data. 


\section{Background}

Starting from early December 2019, cases of human infection with a novel coronavirus were identified in Wuhan, Hubei Province, China. It spreads rapidly to other cities and numerous countries by human-tohuman transmission [1-3]. This disease has been deemed as a public health emergency of global concern by the cause of coronavirus disease 2019 (COVID-19) [4]. Confirmed by high-throughput sequencing, COVID19 is caused by Severe Acute Respiratory Syndrome Coronavirus 2 (SARS-CoV-2), a novel beta-coronavirus, showing around 79\% identity with Severe Acute Respiratory Syndrome Coronavirus (SARS-CoV) and 50\% identity with Middle East Respiratory Syndrome coronavirus (MERS-CoV) [5]. It is usually accompanied by pneumonia, fever, non-productive cough and asthenia [6]. Nausea, vomiting, and dyspnea are also found in patients with COVID-19, though these are less common [7]. Patients with severe disease may develop Acute Respiratory Distress Syndrome (ARDS), acute cardiac injury, shock and can require invasive ventilation [8].

Up to now, large numbers of patients with SARSCoV-2 pneumonia had developed into severe cases or even resulted in death [4]. Guan et al. reported findings of 1099 cases with SARS-CoV-2 infection from 552 hospitals in 30 provinces of China and results suggested that $15.7 \%$ of patients had developed severe illness and $1.4 \%$ of patients died [6]. Among those severe cases, 43 patients (24.9\%) were either admitted to ICU, required mechanical ventilation, or died [6]. The median time from onset of symptoms to shortness of breath, an indicator of severe SARS-CoV-2 pneumonia, was 8 days [7]. It was reported that older patients with comorbidities were more likely to develop severe disease $[6,8]$. However, not all older patients with comorbidities convert to severe cases, indicating that there may be other risk factors. Given the rapid spread of SARS-CoV-2 pneumonia and the large threat to public health, this study aims to investigate clinical features and laboratory findings between non-severe and severe patients, thereby exploring predictive factors for severe cases.

\section{Methods}

\section{Study design and patient populations}

This retrospective analysis was conducted using data collected between Jan 21, 2020 and Feb 25, 2020 from Ningbo First Hospital (Zhejiang Province, China) and Jingzhou Central Hospital (Hubei Province, China). Patients with laboratory confirmed diagnoses of SARSCoV-2 and had been admitted to one of the above medical centers were included. All patients were identified by positive results of reverse transcriptase polymerase chain reaction (RT-PCR) on SARS-CoV-2 in lower respiratory specimens. Patients enrolled presented with mild to moderate SARS-CoV-2 pneumonia at baseline. To avoid potential effects of antiviral drugs, the largest cohort of patients were selected for analysis; all were initiated on combination therapy of arbidol and Kaletra. Ethical approvals for this study were obtained from the Ethics Commission of Ningbo First Hospital (2020 R017) and the Ethics Commission of Jingzhou Central Hospital (2020-2 - 19). Written informed consent was waived due to the rapid emergence of this disease and approved by the local ethics committee.

\section{Data collection}

Patients' electronic medical records were reviewed to extract the following information retrospectively. The following data were collected: Demographic characteristics: age, gender and history of chronic disease; Symptoms: temperature, cough, dyspnea, score throat, muscle soreness, fatigue, anorexic, nausea and diarrhea; Laboratory assessments on admission: white blood cell count, peripheral blood lymphocyte (PBL), D-dimer, Alanine aminotransferase (ALT), Aspartate Aminotransferase (AST) and C-reactive protein (CRP); Dates of important events: onset of symptoms, onset of antiviral therapy, admission to hospital time, discharge or death and the date of negative result of viral nucleic acid test; Details of therapeutic regimen: antiviral medicines and use of corticosteroids.

\section{Definitions}

The severity scores were calculated within $48 \mathrm{~h}$ of hospital admission. Patients were divided into two cohorts according to the version of Diagnosis and Treatment of Pneumonia Caused by COVID-19 (version 6) issued by National Health Commission of the People's Republic of China [9]. Cohort 1, patients who did not convert to severe cases; Cohort 2, patients who converted to severe cases. Patients who met at least one of the following criteria were defined as the severe cases [9]: (1). Respiratory rate $\geq 33 / \mathrm{min}$; (2). Oxygen saturation $\leq 94 \%$ in resting state; (3). PO2/FiO2 $\leq 300 \mathrm{mmHg}$; (4). Developed respiratory failure and require mechanical ventilation; (5). Developed shock; (6). Multiple organ dysfunction and requiring ICU care. The duration (in days) from the start of antiviral therapy to clinical recovery was selected as the primary outcome measure. Clinical recovery is defined as the remission of clinical symptoms for at least $72 \mathrm{~h}$, including normalization of respiratory rate $(\leq 24 /$ min on room air), oxygen saturation (>94\% on room air), fever $\left(\leq 37^{\circ} \mathrm{C}\right.$ of axilla, $\leq 37.2^{\circ} \mathrm{C}$ of oral) and cough (no cough or mild cough).

\section{Statistical analysis}

Continuous variables were expressed as mean (SD) or median (IQR) and categorical variables as quantity 
(proportion). The t-test or Mann-Whitney $U$ test was used for comparison of continuous variables. The chisquared $(x 2)$ test was used to compare categorical variables. Logistic regression was performed to assess the usefulness of risk factors in predicting the patients with mild to moderate SARS-CoV-2 pneumonia who would convert to severe cases. The following factors were analyzed to determine their effects: age, sex, fever, time from onset of symptoms to antiviral treatment, comorbidities, CRP, PBL, and use of corticosteroids. Odds Ratios (ORs) and 95\% confidence intervals (CIs) were estimated. A 2 -sided $\alpha$ of $<0.05$ was considered statistically significant. Statistical analyses were conducted using SPSS version 18.0 (SPSS, Chicago, IL, USA) and SAS version 9.4 (SAS Institute, Cary, North Carolina).

\section{Results}

120 patients with SARS-CoV-2 pneumonia had been admitted to Ningbo First Hospital and Jingzhou Central Hospital, among which 58 patients with mild to moderate disease who received the same antiviral drugs were included (Fig. 1). The mean age (SD) of patients was 47.8 years (13.8), where patients aged 40-79 years accounted for $63.8 \%$ (Table 1). 30 (51.7\%) patients were male. $15(25.9 \%)$ cases had underlying chronic diseases, and 9 (15.5\%) had hypertension. Cough (58.6\%), fever $(41.4 \%)$ and fatigue $(31.0 \%)$ were the most common symptoms at onset, followed by muscle soreness (17.2\%) and dyspnea $(15.5 \%)$. A higher prevalence of comorbidities $(34.8 \%$ vs $20.0 \%)$ was observed in patients who converted to severe cases, and more male patients also converted to severe cases (73.9\% vs $37 \cdot 1 \%)$. 25 (43.1\%) patients received methylprednisolone $1-2 \mathrm{mg} / \mathrm{kg}$ per day.

Time from onset of illness to antiviral treatment for Cohort 1 was 3 (IQR 1-7) days and 4 (IQR 2-6) days in Cohort 2 (Table 2). Patients who converted to severe cases were associated with having a lower lymphocyte count (Cohort 1: $1.3 \pm 0.4$, vs Cohort 2: $0.9 \pm 0.4, P=$ 0.0064 ) and a higher CRP (Cohort 1: 4.5 [0.6-10.9] vs Cohort 2: $16 \cdot 8$ [3.9-55.8], $P=0.0041)$ on admission. Compared with non-severe cases, severe patients had a longer time to clinical recovery (Cohort 1: $8.3 \pm 4.7$ vs Cohort 2: $12.9 \pm 4.4, P=0.0011$ ), duration to negative viral nucleic acid test (Cohort 1: $11.8 \pm 5.0$ vs Cohort 2: $15.7 \pm 6.7, \quad P=0.0183$ ), and hospital stay (Cohort 1 : $14.4 \pm 4.3$ vs Cohort 2: $20.7 \pm 1 \cdot 2, P=0.0211$ ).

Multivariate logistic regression indicated that lymphopenia (peripheral blood lymphocyte count $<1.1 \times 10^{9} / \mathrm{L}$ ) is an independent risk factors for patients converting to severe cases, with OR value of 8.0 (95\%CI, 1.5-41.8) converted to severe cases. The OR for converting to severe cases was 1.28 (95\% CI, 1.06-1.54) in patients with a reduced of $0.1 \times 10^{9} / \mathrm{L}$ peripheral blood lymphocyte (Table 3). In addition, the OR for use of corticosteroids in mild to moderate patients with SARS-CoV-2 pneumonia was 0.14 (95\% CI, $0.02-0.80)$ in those who converted to severe cases.

\section{Discussion}

The most common symptoms for SARS-CoV-2 pneumonia at onset of illness were fever and cough, but some patients had presence of dyspnea at a median of 8 days after onset of illness [10]. Dyspnea, usually observed in

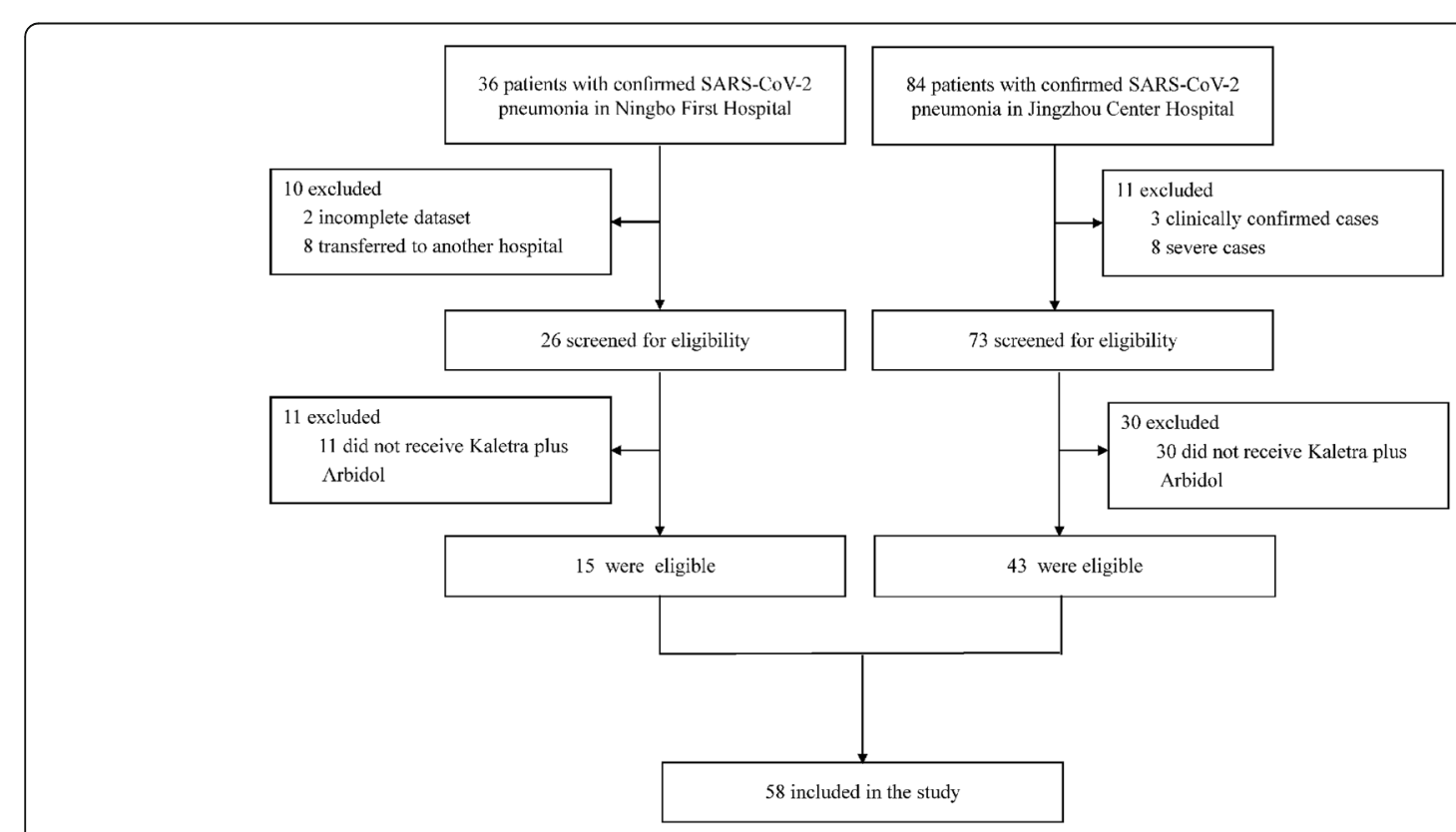

Fig. 1 Flowchart of enrolled patients 
Table 1 Demographics and baseline characteristics of patients with SARS-CoV-2 pneumonia

\begin{tabular}{|c|c|c|c|}
\hline \multirow[t]{2}{*}{ Age, years } & All patients $(n=58)$ & Non-severe $(n=35)$ & Severe $(n=23)$ \\
\hline & $47.8(13.8)$ & $46.0(12 \cdot 7)$ & $50 \cdot 5(15 \cdot 2)$ \\
\hline \multicolumn{4}{|l|}{ Age range, years } \\
\hline $20-29$ & $7(12 \cdot 1 \%)$ & $5(14.3 \%)$ & $2(8 \cdot 7 \%)$ \\
\hline $30-39$ & $13(22 \cdot 4 \%)$ & $8(22 \cdot 9 \%)$ & $5(21 \cdot 7 \%)$ \\
\hline $40-49$ & $9(15 \cdot 5 \%)$ & $6(17 \cdot 1 \%)$ & $3(13.0 \%)$ \\
\hline $50-59$ & 19 (32.8\%) & $11(31 \cdot 4 \%)$ & $8(34 \cdot 8 \%)$ \\
\hline $60-69$ & $7(12 \cdot 1 \%)$ & $5(14 \cdot 3 \%)$ & $2(8.7 \%)$ \\
\hline $70-79$ & $2(3 \cdot 5 \%)$ & 0 & $2(8 \cdot 7 \%)$ \\
\hline$\geq 80$ & $1(1 \cdot 7 \%)$ & 0 & $1(4 \cdot 4 \%)$ \\
\hline \multicolumn{4}{|l|}{ Gender } \\
\hline Female & $28(48 \cdot 3 \%)$ & $22(62.9 \%)$ & $6(26 \cdot 1 \%)$ \\
\hline Male & $30(51 \cdot 7 \%)$ & $13(37 \cdot 1 \%)$ & $17(73.9 \%)$ \\
\hline \multicolumn{4}{|l|}{ Comorbidities } \\
\hline None & $43(74 \cdot 1 \%)$ & $28(80 \cdot 0 \%)$ & $15(65 \cdot 2 \%)$ \\
\hline Hypertension & $9(15 \cdot 5 \%)$ & $4(11 \cdot 4 \%)$ & $5(21 \cdot 7 \%)$ \\
\hline Diabetes & $1(1.7 \%)$ & 0 & $1(4 \cdot 4 \%)$ \\
\hline Chronic kidney disease & $1(1.7 \%)$ & 0 & $1(4 \cdot 4 \%)$ \\
\hline Malignancy & $1(1.7 \%)$ & 0 & $1(4 \cdot 4 \%)$ \\
\hline Others & $5(8 \cdot 6 \%)$ & $3(8 \cdot 6 \%)$ & $2(8 \cdot 7 \%)$ \\
\hline \multicolumn{4}{|l|}{ Symptoms } \\
\hline Fever & $24(41 \cdot 4 \%)$ & $12(34 \cdot 3 \%)$ & $12(52 \cdot 2 \%)$ \\
\hline Cough & $34(58 \cdot 6 \%)$ & $22(62.9 \%)$ & $12(52 \cdot 2 \%)$ \\
\hline Sore throat & $6(10 \cdot 3 \%)$ & $2(5 \cdot 7 \%)$ & $4(17.4 \%)$ \\
\hline Nausea & $6(10 \cdot 3 \%)$ & $5(14 \cdot 3 \%)$ & $1(4 \cdot 4 \%)$ \\
\hline Anorexic & $5(8 \cdot 6 \%)$ & $4(11.4 \%)$ & $1(4 \cdot 4 \%)$ \\
\hline Diarrhea & $4(6 \cdot 9 \%)$ & $3(8 \cdot 6 \%)$ & $1(4 \cdot 4 \%)$ \\
\hline Muscle soreness & $10(17 \cdot 2 \%)$ & $6(17 \cdot 1 \%)$ & $4(17.4 \%)$ \\
\hline Dyspnea & $9(15 \cdot 5 \%)$ & $4(18.2 \%)$ & $5(23 \cdot 8 \%)$ \\
\hline Fatigue & $18(31.0 \%)$ & $10(28 \cdot 6 \%)$ & $8(34 \cdot 8 \%)$ \\
\hline \multicolumn{4}{|l|}{ Severity of cough } \\
\hline Absent & $24(41 \cdot 4 \%)$ & $13(37 \cdot 1 \%)$ & $11(47 \cdot 8 \%)$ \\
\hline Mild & $10(17 \cdot 2 \%)$ & $9(25 \cdot 7 \%)$ & $1(4 \cdot 4 \%)$ \\
\hline Moderate & $18(31.0 \%)$ & $10(28 \cdot 6 \%)$ & $8(34 \cdot 8 \%)$ \\
\hline Severe & $6(10 \cdot 3 \%)$ & $3(8 \cdot 6 \%)$ & $3(13.0 \%)$ \\
\hline
\end{tabular}

Footnote: Data are $\mathrm{n}(\%)$, mean (SD) or median (IQR), unless otherwise stated

severe patients with SARS-CoV-2 pneumonia [11], may indicate the progression of disease with a low oxygenation index and a state of severe illness. However, up to now, the clinical course of SARS-CoV-2 pneumonia and risk factors for converting to severe cases remain unknown.

This study was performed to investigate clinical characteristics of patients with severe SARS-CoV-2 pneumonia, and identify risk factors for those with mild to moderate disease who converted to severe cases. 120 patients (36 from Ningbo First Hospital and 84 from Jingzhou Central Hospital) were included in this study, among which 62 were excluded and 58 were included in the final analysis. The results from this study showed that low peripheral blood lymphocyte count $\left(<1.1 \times 10^{9}\right)$ $\mathrm{L})$ was an independent risk factor for patients converting to severe cases (OR: 8.0, 95\% CI: 1.5-41.8). With each reduction of $0.1 \times 10^{9} / \mathrm{L}$ in peripheral blood lymphocyte count, the OR for converting to severe cases increased $28 \%$ (95\% CI, 6-54\%). In addition, using of 
Table 2 Laboratory findings, corticosteroid usage, and hospital course in patients with SARS-CoV-2 pneumonia

\begin{tabular}{|c|c|c|c|}
\hline & Non-severe $(n=35)$ & Severe $(n=23)$ & $P$ value \\
\hline \multicolumn{4}{|l|}{ Laboratory findings } \\
\hline WBCs count, $\times 10^{9} / \mathrm{L}$ & $5.1(1.9)$ & $5 \cdot 9(4 \cdot 1)$ & 0.3 \\
\hline Lymphocyte count, $\times 10^{9} / \mathrm{L}$ & $1.3(0.4)$ & $0.9(0.4)$ & 0.0 \\
\hline C-reactive protein, mg/L & $4.5(0.6-10 \cdot 9)$ & $16 \cdot 8(3 \cdot 9-55 \cdot 8)$ & 0.0 \\
\hline D-dimer, mg/L & $90 \cdot 0(45 \cdot 5-180 \cdot 0)$ & $154 \cdot 0(113 \cdot 3-470 \cdot 5)$ & $0 \cdot 1$ \\
\hline ALT level, IU/L & $20 \cdot 9(8.9)$ & $28 \cdot 3(22 \cdot 4)$ & 0.1 \\
\hline AST level, IU/L & $24 \cdot 0(6 \cdot 3)$ & $31.0(13 \cdot 3)$ & 0.0 \\
\hline Corticosteroid usage & & & 0.0 \\
\hline Yes & $11(31 \cdot 4 \%)$ & $14(60 \cdot 9 \%)$ & \\
\hline No & $24(68 \cdot 6 \%)$ & $9(39 \cdot 1 \%)$ & \\
\hline \multicolumn{4}{|l|}{ Hospital course } \\
\hline Time from onset of illness to antiviral treatment, days & $3.0(1.0-7.0)$ & $4.0(2 \cdot 0-6 \cdot 0)$ & 0.6 \\
\hline Clinical recovery time, days & $8 \cdot 3(4 \cdot 7)$ & $12.9(4.4)$ & 0.0 \\
\hline Time of virus nucleic acid turn to negative, days & $11 \cdot 8(5.0)$ & $15 \cdot 7(6 \cdot 7)$ & 0.0 \\
\hline Hospitalization duration, days & $14 \cdot 4(4 \cdot 3)$ & $20 \cdot 7(1 \cdot 2)$ & 0.0 \\
\hline
\end{tabular}

Abbreviations: WBCs, white blood cell counts; ALT, Alanine aminotransferase; AST, Aspartate Aminotransferase

corticosteroids in mild to moderate patients with SARS$\mathrm{CoV}-2$ pneumonia was also associated with a reduced risk of converting to severe cases (OR: $0.14,95 \%$ CI: 0.02-0.80).

Lymphopenia was also observed in most patients with SARS-CoV infection during their course of illness [12, 13]. He et al. believed that lymphopenia was a significant factor of SARS-CoV infection and lymphocyte counts may be useful in predicting the disease severity and clinical outcomes [13]. A recent study reported an absolute lymphopenia (lymphocyte count $<1.0 \times 10^{9} / \mathrm{L}$ ) in $63 \%$ of patients with SARS-CoV-2 pneumonia on admission. Low levels of total lymphocyte counts were more marked in those patients in which infection resulted in death [11]. A possible cause for the lymphopenia may be that lymphocytes are directly infected and destroyed by SARS-CoV-2. However, this requires further study to confirm, as the cellular receptor for SARS-CoV-2 is angiotensin-converting enzyme 2 [14], which is not expressed on B or T lymphocytes [15]. Therefore, depletion of lymphocytes may be secondary to the direct effect of the virus on the lymphocytes or the effect of various cytokine mediated altered lymphocyte trafficking.

Since no antiviral treatment for SARS-CoV-2 infection has been proven to be effective, management of this disease remains clinically based and supportive [16]. Considering that acute viral pneumonia is an important cause of acute lung injury (ALI), the value of systematic corticosteroids in patients with SARS-CoV-2 infection is a focus of interest. This study showed patients who received low-to-moderate dose of systematic corticosteroids were less likely to convert to severe cases. In a report by Chen et al. [17], the use of systematic corticosteroids in SARS resulted in reduced mortality and a shorter hospitalization stay, and was not associated with significant secondary lower respiratory tract infection or other complications. However, it is well known that

Table 3 The risk factors in predicting patients with mild to moderate SARS-CoV-2 pneumonia conversion rate to severe cases

\begin{tabular}{|c|c|c|c|c|c|c|}
\hline Variable & Regression coefficient & Standard error & $P$ value & Odds ratio & Lower OR & Upper OR \\
\hline Age, years & -0.04 & 0.04 & 0.2376 & 0.96 & 0.90 & 1.03 \\
\hline Gender (female vs. male) & $-1 \cdot 38$ & 0.76 & 0.0702 & 0.25 & 0.06 & $1 \cdot 12$ \\
\hline Fever (yes vs. no) & $1 \cdot 13$ & 0.60 & 0.0597 & 3.09 & 0.96 & 9.99 \\
\hline Comorbidities (yes vs. no) & 0.87 & 0.86 & 0.3121 & $2 \cdot 38$ & 0.44 & $12 \cdot 76$ \\
\hline C-reactive protein (< $10 \mathrm{mg} / \mathrm{L}$ vs. $\geqq 10 \mathrm{mg} / \mathrm{L})$ & 0.38 & 0.75 & 0.6145 & 1.46 & 0.33 & $6 \cdot 40$ \\
\hline Lymphocyte count (per reduced $0.1 \times 10^{9} / \mathrm{L}$ ) & -0.25 & 0.09 & 0.0070 & 0.78 & 0.65 & 0.94 \\
\hline Time from onset of illness to antiviral treatment, days & 0.03 & 0.06 & 0.6670 & 1.03 & 0.91 & $1 \cdot 17$ \\
\hline Corticosteroids (yes vs. no) & -1.99 & 0.90 & 0.0275 & 0.14 & 0.02 & 0.80 \\
\hline
\end{tabular}


corticosteroid therapy is a double-edged sword $[18,19]$. The immune response may be weak and consequently have more difficulty in eradicating the virus because of treatment with systematic corticosteroids [20]. Further studies are urgently required to assess whether systematic corticosteroid treatment is beneficial in patients with SARS-CoV-2 pneumonia.

Some limitations of this study should be acknowledged. Firstly, this was a retrospective study with a limited sample size, if the conclusion generalized is to be widely used, it would still need a prospective large-scale clinical validation. Secondly, different varieties of traditional Chinese medicine were administered to most patients, and the effectiveness and potential adverse effects of those drugs given remain largely unknown. Thirdly, examinations of lymphocyte subsets were undertaken in this study, and in addition, total lymphocyte counts were not observed dynamically. Despite the above limitations, our study has shown the predictors of severe cases in mild to moderate patients with SARS-CoV-2 pneumonia. This may help clinicians more accurately predict prognosis, and triage priorities to improve clinical outcomes.

\section{Conclusions}

The findings from this study showed that low lymphocyte count $\left(<1.1 \times 10^{9} / \mathrm{L}\right)$ in peripheral blood was an independent risk factor for patients who converted to severe cases. In addition, using of systematic corticosteroids in mild to moderate patients with SARS-CoV-2 pneumonia was associated with a reduced risk of converting to severe cases. However, this study was carried out right after the start of the pandemic with a small sample size. Further prospective studies are warranted to confirm these findings.

\section{Abbreviations}

WHO: World Health Organization; COVID-19: Coronavirus infected disease 2019; SARS-CoV-2: Severe Acute Respiratory Syndrome Coronavirus 2; SARSCoV: Severe Acute Respiratory Syndrome Coronavirus; MERS-CoV: Middle East Respiratory Syndrome coronavirus; ARDS: Acute Respiratory Distress Syndrome; ALI: Acute lung injury

\section{Acknowledgements}

The authors would like to Phoebe Jaye Miles for writing assistance and revised of the manuscript.

\section{Authors' contributions}

CC, LH, JM, LY, and CZ collected the epidemiological and clinical data. CC and $M C$ processed statistical data. YL, QJ, SW, WH, GQ, JC, and XC summarized all data. CC and JM drafted the manuscript, CC, LH and XC reviewed the final manuscript. The author(s) read and approved the final manuscript.

\section{Funding}

This work was supported by Medical and health plan of Zhejiang Province (2019324432). The funder of the study had no role in study design, analysis, interpretation of the data, or writing of the report.
Availability of data and materials

The datasets used and/or analysed during the current study are available from the corresponding author on reasonable request.

\section{Declarations}

\section{Ethics approval and consent to participate}

Ethical approvals for this study were obtained from the Ethics Commission of Ningbo First Hospital (2020 - R017) and the Ethics Commission of Jingzhou Central Hospital (2020-2 - 19). Written informed consent was waived due to the rapid emergence of this disease and approved by the local ethics committee.

\section{Consent for publication \\ Not applicable.}

\section{Competing interests}

All authors declare no competing interests.

\section{Author details}

${ }^{1}$ Department of Respiratory and Critical Medicine, Ningbo First Hospital Ningbo, China. ${ }^{2}$ Department of Respiratory and Critical Medicine, Jingzhou Central Hospital, the Second Clinical Medical College, Yangtze University, Jingzhou, China. ${ }^{3}$ Department of Cardiology, Ningbo First Hospital, 59 Liuting Road, Ningbo, Zhejiang, China.

Received: 24 June 2020 Accepted: 17 June 2021

Published online: 08 July 2021

\section{References}

1. Zhu N, Zhang D, Wang W, Li X, Yang B, Song J, et al. A novel coronavirus from patients with pneumonia in China, 2019. N Engl J Med. 2020;382(8): 727-33. https://doi.org/10.1056/NEJMoa2001017.

2. Rothe C, Schunk M, Sothmann P, Bretzel G, Froeschl G, Wallrauch C, et al. Transmission of 2019-nCoV infection from an asymptomatic contact in Germany. N Engl J Med. 2020;382(10):970-1. https://doi.org/10.1056/NEJMc2 001468

3. Xu X-W, Wu X-X, Jiang X-G, Xu K-J, Ying L-J, Ma C-L, et al. Clinical findings in a group of patients infected with the 2019 novel coronavirus (SARS-Cov-2) outside of Wuhan, China: retrospective case series. BMJ. 2020;368:m606. https://doi.org/10.1136/bmj.m606.

4. WHO. Coronavirus disease (COVID-19) outbreak. December 31, 2019. https:// www.who.int/emergencies/diseases/novel-coronavirus-2019 (accessed 15 February 2020).

5. Lu R, Zhao X, Li J, Niu P, Yang B, Wu H, et al. Genomic characterisation and epidemiology of 2019 novel coronavirus: implications for virus origins and receptor binding. Lancet. 2020;395(10224):565-74. https://doi.org/10.1016/ S0140-6736(20)30251-8.

6. Guan WJ, Ni ZY, Hu Y, Liang WH, Ou CQ, He JX, et al. Clinical characteristics of coronavirus disease 2019 in China. N Engl J Med. 2020;382(18):1708-20. https://doi.org/10.1056/NEJMoa2002032.

7. Huang C, Wang Y, Li X, Ren L, Zhao J, Hu Y, et al. Clinical features of patients infected with 2019 novel coronavirus in Wuhan, China. Lancet. 2020;395(10223):497-506. https://doi.org/10.1016/\$0140-6736(20)30183-5.

8. Wu Z, McGoogan J. Characteristics of and important lessons from the coronavirus disease 2019 (COVID-19) outbreak in China: summary of a report of 72314 cases from the Chinese Center for Disease Control and Prevention. JAMA. 2020;323(13):1239-42. https://doi.org/10.1001/jama.2020.2 648.

9. China NHCotPsRo. Diagnosis and Treatment of Pneumonia Caused by COVID-19. . (http://www.nhc.gov.cn/yzygj/s7653p/202002/8334a8326dd94 d329df351d7da8aefc2.shtml). (accessed 19 February 2020).

10. Huang C, Wang Y, Li X, Ren L, Zhao J, Hu Y, et al. Clinical features of patients infected with 2019 novel coronavirus in Wuhan, China. Lancet. 2020;395(10223):497-506. https://doi.org/10.1016/S0140-6736(20)30183-5.

11. Yang $X, Y u$ Y, Xu J, Shu H, Xia Ja, Liu H, et al. Clinical course and outcomes of critically ill patients with SARS-CoV-2 pneumonia in Wuhan, China: a single-centered, retrospective, observational study. Lancet Respir Med. 2020; 8(5):475-81. https://doi.org/10.1016/\$2213-2600(20)30079-5

12. Wong RSM, Wu A, To KF, Lee N, Lam CWK, Wong CK, et al. Haematological manifestations in patients with severe acute respiratory syndrome: 
retrospective analysis. BMJ (Clin Res ed). 2003;326(7403):1358-62. https://doi. org/10.1136/bmj.326.7403.1358.

13. He Z, Zhao C, Dong Q, Zhuang H, Song S, Peng G, et al. Effects of severe acute respiratory syndrome (SARS) coronavirus infection on peripheral blood lymphocytes and their subsets. Int J Infect Dis. 2005;9(6):323-30. https://doi.org/10.1016/j.ijid.2004.07.014

14. Yan R, Zhang Y, Li Y, Xia L, Guo Y, Zhou Q. Structural basis for the recognition of the SARS-CoV-2 by full-length human ACE2. Science. 2020; 367(6485):1444-8. https://doi.org/10.1126/science.abb2762

15. To KF, Lo AWI. Exploring the pathogenesis of severe acute respiratory syndrome (SARS): the tissue distribution of the coronavirus (SARS-CoV) and its putative receptor, angiotensin-converting enzyme 2 (ACE2). J Pathol. 2004;203(3):740-3. https://doi.org/10.1002/path.1597.

16. Fu Y, Cheng Y, Wu Y. Understanding SARS-CoV-2-mediated inflammatory responses: from mechanisms to potential therapeutic tools. Virol Sin. 2020 https://doi.org/10.1007/s12250-020-00207-4.

17. Chen R-C, Tang X-P, Tan S-Y, Liang B-L, Wan Z-Y, Fang J-Q, et al. Treatment of severe acute respiratory syndrome with glucosteroids: the Guangzhou experience. Chest. 2006;129(6):1441-52. https://doi.org/10.1378/chest.129. 6.1441.

18. Shang L, Zhao J, Hu Y, Du R, Cao B. On the use of corticosteroids for 2019nCoV pneumonia. Lancet. 2020;395(10225):683-4. https://doi.org/10.1016/ S0140-6736(20)30361-5.

19. Russell CD, Millar JE, Baillie JK. Clinical evidence does not support corticosteroid treatment for 2019-nCoV lung injury. Lancet. 2020;395(10223): 473-5. https://doi.org/10.1016/50140-6736(20)30317-2.

20. Hui DS, Lee N, Chan PK, Beigel JH. The role of adjuvant immunomodulatory agents for treatment of severe influenza. Antivir Res. 2018;150:202-16. https://doi.org/10.1016/j.antiviral.2018.01.002.

\section{Publisher's Note}

Springer Nature remains neutral with regard to jurisdictional claims in published maps and institutional affiliations.

Ready to submit your research? Choose BMC and benefit from:

- fast, convenient online submission

- thorough peer review by experienced researchers in your field

- rapid publication on acceptance

- support for research data, including large and complex data types

- gold Open Access which fosters wider collaboration and increased citations

- maximum visibility for your research: over $100 \mathrm{M}$ website views per year

At $\mathrm{BMC}$, research is always in progress.

Learn more biomedcentral.com/submissions 